\title{
The Impact of the Bass Drum on Human Dance Movement
}

Edith Van Dyck, Dirk Moelants, Michiel Demey, Alexander Deweppe, Pieter Coussement \& Marc LEMAN

Ghent University, Ghent, Belgium

The PResent STUdy AIMS TO GAIN BETTER INSIGHT into the connection between music and dance by examining the dynamic effects of the bass drum on a dancing audience in a club-like environment. One hundred adult participants moved freely in groups of five to a musical sequence that comprised six songs. Each song consisted of one section that was repeated three times, each time with a different sound pressure level of the bass drum. Hip and head movements were recorded using motion capture and motion sensing. The study demonstrates that people modify their bodily behavior according to the dynamic level of the bass drum when moving to contemporary dance music in a social context. Participants moved more actively and displayed a higher degree of tempo entrainment as the sound pressure level of the bass drum increased. These results indicate that the prominence of the bass drum in contemporary dance music serves not merely as a stylistic element; indeed, it has a strong influence on dancing itself.

Received: July 13, 2011, accepted May 29, 2012.

Key words: dance, bass drum, activity count, entrainment, joint action

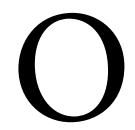
NE OF THE MAIN EFFECTS OF MUSIC IS THAT it supports dance movement. Dance is movement of the human body in response to, and in interaction with, music (Ulyate \& Bianciardi, 2002). Dance behavior might be a product of evolutionary forces (Phillips-Silver et al., 2011), as dancing together with other human beings could increase group cohesion (Merker, Madison, \& Eckerdal, 2009; Wiltermuth \& Heath, 2009). It may also have a function in sexual selection (Darwin, 1871), as dance attractiveness could signal phenotypic quality (Brown et al., 2005). The oldest depiction of dance dates back 20,000 years
(Appenzeller, 1998), although dance is believed to be as old as the human capacities for bipedal walking and running, which are two to five million years old (Bramble \& Lieberman, 2004; Ward, 2002).

It has been suggested that while dancing, humans tend to generate corporeal articulations in response to the auditory stimulus (Leman, 2007). Unlike linguistic description, these are believed to be capable of accurately describing or translating musical experience (Bengtsson, 1973). Just as people tend to imitate the behavior of another person in their own actionoriented ontology in order to understand it, they can mirror changes in sound energy through body movement (Leman, 2007). As imitation is believed to be a well-developed and innate human characteristic that fosters learning and yields pleasure (McKeon, 2001), corporeal imitations of an auditory stimulus are assumed to facilitate a better understanding and a more pleasurable and satisfactory experience of music. Although the precise mechanisms by which acoustical features generate an effect on body movement are little understood (Madison, Gouyon, Ullén, \& Hörnström, 2011), it is known that humans tend to be capable of imitating a wide variety of structural layers in music, such as harmony, rhythm, and melody (Leman, 2007). For instance, in a study of running, Edworthy and Waring (2006) explored the effect of tempo and sound pressure level of music on a treadmill exercise. Participants had to perform exercises on a treadmill while listening to a musical stimulus that was presented either fast/ loud, fast/quiet, slow/loud, slow/quiet, or was absent. The study showed that increasing the tempo, and to a lesser extent, increasing the loudness of music, tends also to increase running speed. Further to this, the effect of musical cues on corporeal articulations is also observable in more localized body areas; for example, in the proclivity to tap along with the beat of the music (Repp, 2005).

Aside from corporeal articulations in response to music, joint action or global group attuning can occur, as dancing most often takes place in social contexts (Leman, 2007). Kirschner and Tomasello (2010) suggested that moving to music encourages dancers to maintain a constant audiovisual representation of the mutual intention and goal of dancing, which satisfies the intrinsic human desire to share emotions,

Music Perception, volume 30, issue 4, pp. 349-359, issn 0730-7829, electronic issn 1533-8312. C 2013 by the Regents of the university of California all RIGHTS RESERVED. PLEASE DIRECT ALL REQUESTS FOR PERMISSION TO PHOTOCOPY OR REPRODUCE ARTICLE CONTENT THROUGH THE UNIVERSITY OF CALIFORNIA PRESS'S RIGHTS AND PERMISSIONS WEBSITE, HTTP://WWW.UCPRESSJOURNALS.COM/REPRINTINFO.ASP. DOI: 10.1525/MP.2013.30.4.349 
experiences, and activities with others. De Bruyn, Leman, Moelants, and Demey (2009) sought to quantify the effect of social interaction on dance movements made both by individuals and groups of participants. Results showed that social context not only stimulates participants to entrain more closely with and to move more actively to music, but it also increases the entrainment of the movements between the individuals. A common case of small-scale joint action is when someone is walking with a friend and suddenly becomes aware that they are not in step. As a result, he or she tries to get in step in order to be 'with' that person. On the other hand, when someone discovers that his or her footsteps are in sync with those of a total stranger, this can create a sense of intimacy that feels awkward. Therefore, he or she will try to get out of step (Gill, 2007). Joint action in large groups can be observed during pop concerts where people often synchronize dance movements. Other products of global group attuning are drum circles, where people gather to drum together with the intention of sharing rhythm and entraining their performances and movements to one another in order to form a group consciousness (Phillips-Silver, Aktipis, \& Bryant, 2010).

As humans have the capacity to become attuned both to musical stimuli and to each other, there is perhaps no stronger behavior to unite humans than coordinated rhythmic movement (Phillips-Silver et al., 2010). Throughout history, both coordinated rhythmic movement and the shared feelings it evokes have proved their potency in holding groups together (McNeill, 1995). The driving force behind this phenomenon is motor entrainment, i.e., the ability to align motor actions with external rhythms (Brown, Martinez, \& Parsons, 2006). In that context, Toiviainen, Luck, and Thompson (2010) showed that several levels of the metrical hierarchy of music are simultaneously embodied in the movements of dancers. Large and Jones (1999) consider entrainment where parts of the dancer match up with certain time spans in the music as a means of understanding or, as they state, knowing the music. Several studies imply that the capacities to perceive and entrain to a beat or to a musical tempo rely on a network of auditory, motor, and vestibular systems (Janata \& Grafton, 2003; Phillips-Silver \& Trainor, 2008; Trainor, Gao, Lei, Lehtovaara, \& Harris, 2009; Zatorre, Chen, \& Penhune, 2007). On the other hand, there is also evidence to suggest that gestures affect beat perception, as Phillips-Silver and Trainor (2007) discovered that the human encoding of meter could be affected by passive movements of the body.
The present work is an empirical investigation into the phenomenon of motor entrainment, as it occurs in actual dance clubs. Dance clubs have become a significant part of the entertainment scene for many young adults, and attending such clubs (clubbing) has become a common recreational activity for many young people (Williams, Beach, \& Gilliver, 2010). In this dance scene, it is common practice to enhance music with loud low-frequency beats (e.g., by turning up the volume in the low-frequency domain), or the so-called bass drum, in order to encourage the audience to move. The significance of the bass drum in contemporary music is also manifested through the popular trend of adding components (e.g., subwoofers) to home or automobile stereo systems for the sole purpose of intensifying audio bass reproduction (McCown, Keiser, Mulhearn, \& Williamson, 1997). According to Todd, Cody, and Banks (2000), a loud bass drum may affect the vestibular system and subsequently, also the sense of motion. These researchers suggested that acoustically evoked sensations of self-motion may to a certain extent account for the compulsion to expose oneself to loud bass drum sound. It has also been shown that listening to rhythms with a strong beat engages motor areas in the brain (Chen, Penhune, \& Zatorre, 2008; Grahn \& Brett, 2007). More specifically, Large and Kolen (1994) suggested that events with greater accent (e.g., intensity) could cause greater phase and period adjustments. In addition to affecting movement, a loud bass drum sound could elicit sensations of pleasure. Continuous stimuli with frequencies between about $50-800 \mathrm{~Hz}$ above about $90 \mathrm{~dB}$ may evoke a continuous response in the saccular nerve (Todd et al., 2000). When the sacculus, which is part of the vestibular system, is stimulated, sensations of pleasure arise through interaction with the limbic system. By activating the sacculus, loud music with a strong beat may be a form of vestibular stimulation. Percussive sounds are also expected to have a power distribution in the region of saccular sensitivity. Thus, the typical intensities and frequency distributions in dance clubs might be considered to be intended to stimulate the sacculus (Dibble, 1995).

Motor entrainment has been studied extensively, although only a few experiments have been executed with more than one participant at a time (Drake, Penel, \& Bigand, 2000; Snyder \& Krumhansl, 2001; Toiviainen, Luck, \& Thompson, 2010), and consequently, they have overlooked the social aspect of entrainment, or joint action, despite the fact that motor entrainment usually takes place in social contexts (Kirschner \& Tomasello, 2010; Repp \& Keller, 2008). Therefore, in this study, the 
experiments were performed in groups of participants, in order to replicate the situation of a dance club.

This study examines the impact of the sound pressure level of the bass drum (the beat presented in the low frequency domain) on a dancing audience. In view of the fact that a loud bass drum can affect the vestibular system, and subsequently also the sense of motion (Todd et al., 2000), we expected bass drum loudness to affect human movement. As Edworthy and Waring (2006) revealed that loud music can enhance optimal exercising, we presumed that an increase in the sound pressure level of the bass drum could lead to an increase in motor activity. Moreover, the effect on tempo entrainment is considered. Large and Kolen (1994) suggested that events with greater accent could cause greater period adjustments. Therefore, we expected that an increase in bass drum loudness could improve tempo entrainment. Additionally, as the experiment was performed in groups, social interaction was presumed to have an effect on participants' movements. Consequently, we expected to uncover an effect of joint action, in the form of an increased similarity of movements between members of the same group compared to movements between members of different groups. Finally, the effect of sex is examined. As Passmore and French (2001) revealed that females are more likely to actively engage in dance activities than men, we expected female participants to display more active dance movements than male participants.

\section{Method}

\section{PARTICIPANTS}

A total of 100 adult participants (50 females, 50 males) with an average age of 25.43 years $(S D=8.01)$ took part in the study. All participants had normal hearing capacities. The majority $(72 \%)$ had received music lessons: at a music school (65\%), a conservatory (4\%), or via private music lessons (3\%). Of all participants, $85 \%$ reported enjoying dancing ( $9 \%$ danced about once a year or less; $33 \%$ about once a month; $43 \%$ about once a week or more), and $35 \%$ had received dance training. All participants signed a form to declare that they participated voluntarily and that they had received sufficient information concerning the tasks, the procedures, and the technologies used. As a reward, they received a $\mathrm{CD}$ voucher.

\section{MUSIC}

The music for the experiment consisted of a club-like mix, conceived as a concatenation of six electronic pieces (here referred to as songs), composed exclusively for this study. The choice to use new and unknown music was motivated by the intention of ensuring optimal control over all musical parameters and to exclude effects of familiarity. The composition had a fixed tempo of $128 \mathrm{BPM}$, which represents the most common tempo in contemporary dance music (Moelants, 2008). Every beat of the bass drum sounded identical, which means that no single one was any more stressed than the others.

The music was composed in a $4 / 4$ meter, and in the key of A minor. The key remained unaltered throughout all six songs. The composition comprised two independent instrumental parts. One contained all the melodic material, consisted of two lead synthesizers (in the mid section of the frequency range) and had relatively simple chord progressions, similar to those used in popular house and techno records. The other instrumental part consisted of a stable basic bass drum.

Each of the six songs consisted of three loops of a 16-bar core-motive (30"), different for each song (see Figure 1). This motive appeared three times in the course of the stimulus, featuring three different sound pressure levels of the bass drum (bass drum levels, BDLs). The order of the different BDLs was determined in such a way that it would ensure that each possible series of levels would occur only once. When producing the mix, the reference level of the bass drum (i.e., the intermediate level, BDL 2) was determined by giving the bass drum a clear presence in the mix, resembling modern dance productions, and without affecting the global sound pressure level (SPL) of the mix. At the lower $(-5 \mathrm{~dB})$ level (BDL 1), the bass drum faded further into the background of the mix, whereas the higher $(+5 \mathrm{~dB})$ level (BDL 3$)$ made the bass drum more prominent.

Finally, three points in the music were chosen where the bass drum was presented without accompaniment for $15 \mathrm{~s}$, each with a different SPL, serving as a point of reference for the analysis. These solo parts were placed between the second and third song, between the third and fourth song, and between the fourth and fifth song. Hence, the mix consisted of 21 blocks and had a length of $9 \mathrm{~min}$ and $45 \mathrm{~s}$. Additionally, a short introduction (15") was added to avoid a start-up-effect in the first song, whereas a fade-out (30") was added at the end of the composition. The introduction and the fade-out were not taken into account in the analysis.

\section{APPARATUS}

Participants were fitted with a hip bag containing a wireless Nintendo Wii remote controller and wore a hat with three reflective markers for position tracking with 


\begin{tabular}{|c|c|c|c|}
\hline Intro & $15 "$ & & \\
\hline \multirow{2}{*}{ Song 1} & BDL 2 & BDL 3 & BDL 1 \\
\hline & $30 "$ & $30 "$ & $30 "$ \\
\hline \multirow{2}{*}{ Song 2} & BDL 1 & BDL 2 & BDL 3 \\
\hline & $30 "$ & $30 "$ & $30 "$ \\
\hline \multirow{2}{*}{ Solo 1} & & BDL 2 & \\
\hline & & $15 "$ & \\
\hline \multirow{2}{*}{ Song 3} & BDL 3 & BDL 1 & BDL 2 \\
\hline & $30 "$ & $30 "$ & $30 "$ \\
\hline \multirow{2}{*}{ Solo 2} & & BDL 1 & \\
\hline & & $15 "$ & \\
\hline \multirow{2}{*}{ Song 4} & BDL 3 & BDL 2 & BDL 1 \\
\hline & $30 "$ & $30 "$ & $30 "$ \\
\hline \multirow{2}{*}{ Solo 3} & & BDL 3 & \\
\hline & & $15 "$ & \\
\hline \multirow{2}{*}{ Song 5} & BDL 1 & BDL 3 & BDL 2 \\
\hline & $30 "$ & $30 "$ & $30 "$ \\
\hline \multirow{2}{*}{ Song 6} & BDL 2 & BDL 1 & BDL 3 \\
\hline & $30 "$ & $30 "$ & $30 "$ \\
\hline Outro & $30 "$ & & \\
\hline
\end{tabular}

FIGURE 1. Overview of the succession of the different BDLs in the musical stimulus.

a motion capture system (Optitrack, Natural Point). Acceleration data from the remote controller were recorded at a sampling rate of $100 \mathrm{~Hz}$ using a Max/MSP patch, the resultant recording being synchronized with the playback of the musical stimulus. The 3D position of the head was also tracked at a sampling rate of $100 \mathrm{~Hz}$. In order to be able to synchronize the audio playback and the motion capture recordings, the control of an Arduino card was incorporated in the Max/MSP patch. The Arduino card controlled IR (infrared) LEDs, detected in the motion capture data as markers. The IR LEDs were switched on at the moment the audio playback was started, defining the onset in the motion capture data. The music was played through four Metro MX100 loudspeakers, placed in every corner of the dance floor just behind the curtains. The space was equipped with basic club-style lighting, including sound-sensitive light effects. The light effects responded to sound in general and did not stress the bass drum. Figure 2 depicts a group of participants performing the experiment in the experimental room where they were shielded from the outside world by black curtains and where colorful lighting contributed to create a club-style atmosphere.

Mean SPL and peaks in the SPL of the music were measured by means of a Svantek SVAN 959 sound and vibration analyzer. Measurements demonstrated that the overall $\mathrm{dB}(\mathrm{A})$ level (see upper graph in Figure 3) remained below the legally permitted Belgian limit of 90 $\mathrm{dB}(\mathrm{A})$. On the authority of the National Institute for Occupational Safety and Health's (NIOSH) (http:// cdc.gov/niosh/) chart of loudness and exposure time, a maximum exposure of $8 \mathrm{hr}$ per day at $85 \mathrm{~dB}(\mathrm{~A})$ is allowed. No direct relationship between the BDL and changes in the global $\mathrm{dB}(\mathrm{A})$ was noticeable (except during the solo parts), as shown in the upper graph of Figure 3. The lower graph illustrates the SPL at $63 \mathrm{~Hz}$ (bass drum sound).

\section{PROCEDURE}

The experimental sessions took place in the late afternoon or evening. Participants were invited in groups of five. Upon their arrival, they were offered refreshments and were asked to complete a form with questions about 


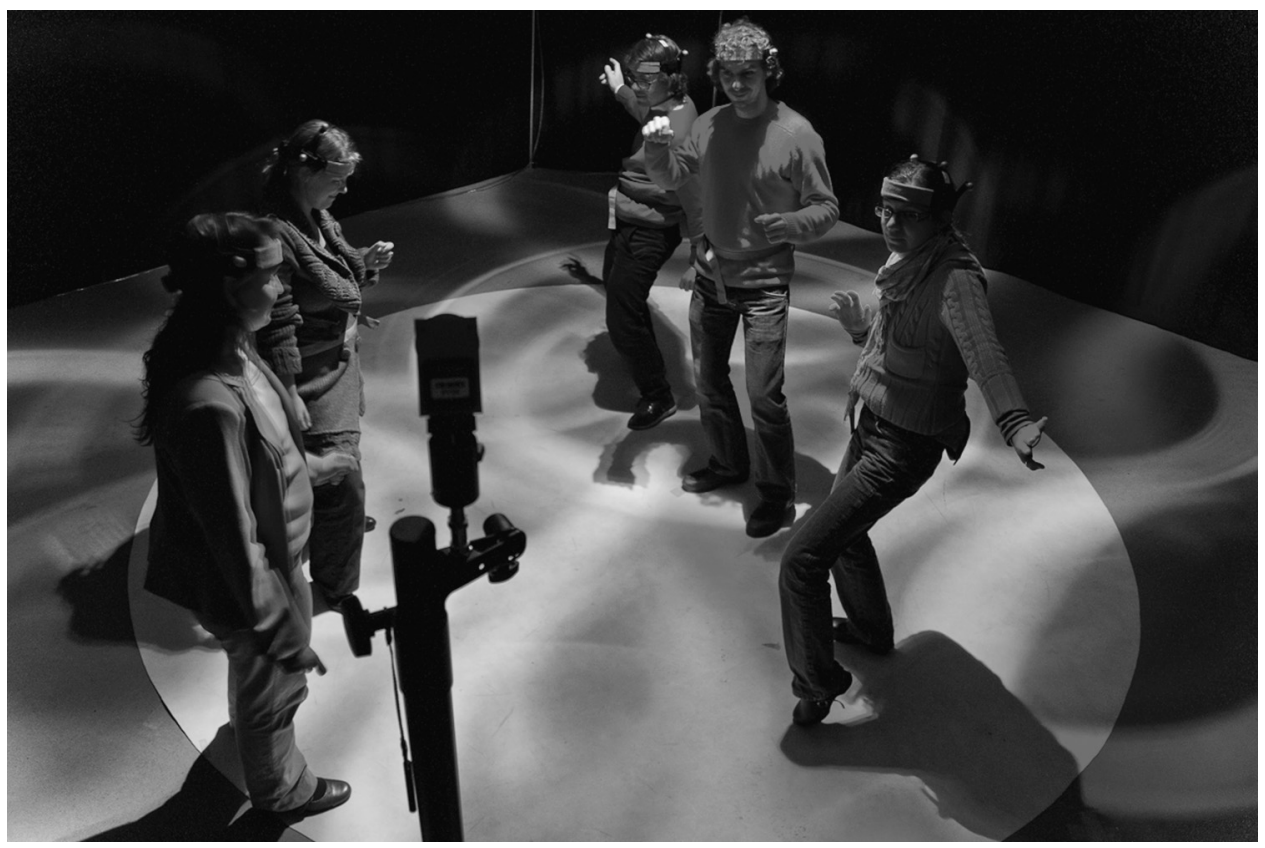

FIGURE 2. Group of participants performing the experiment accompanied by sound-sensitive light effects.

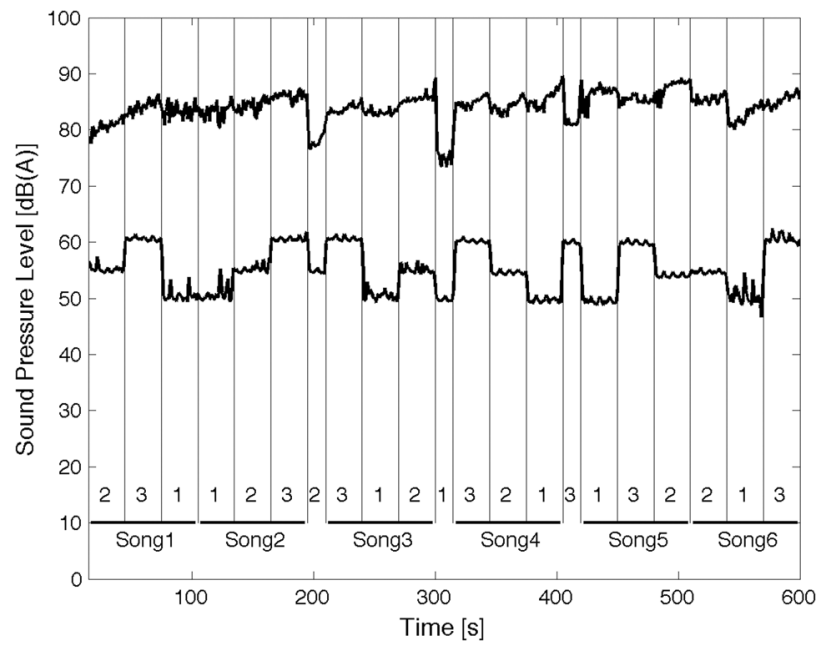

FIGURE 3. Overview of the SPL for each song and BDL, the upper graph representing the global $\mathrm{dB}(\mathrm{A})$ level, the lower graph illustrating the $\mathrm{dB}(\mathrm{A})$ level at $63 \mathrm{~Hz}$.

their personal background and their music and dance preferences and training. After having been fitted with the movement tracking equipment, participants were directed to a dance floor surrounded by black curtains. Next, they were instructed to move freely to the music. After the experiment, they were asked to complete a second questionnaire that included items concerning the participants' impressions of the experiment. Participants had to elaborate on their appreciation of the musical stimulus, the lighting effects, and the general ambience. The total duration of the experiment was about $30 \mathrm{~min}$.

\section{DATA PROCESSING}

The measurements aimed at extracting two parameters - called activity count and tempo entrainment - from the movement data. Activity count was extracted from acceleration data. For that purpose, we measured the 3D acceleration of the hips, using the remote controller attached to the hips. Tempo entrainment was extracted from displacement data. For that aim, the 3D displacement of the head was measured, using the motion capture system. The choice of body parts was based on a pilot study where head and hips indeed proved to be the most reliable body parts for the parameters we wanted to extract. Moreover, foot, leg, and arm movements depended on the dominance of the right or left foot, leg, or arm whereas the head and hips did not display a similar lateral dominance.

Activity count. Activity count concerns a quantity commonly used in studies related to actigraphy, where motor activity is monitored. This quantity could be calculated on the basis of a digital integration of the acceleration signal. First, the acceleration was filtered using a band-pass filter between $0.5 \mathrm{~Hz}$ and $4 \mathrm{~Hz}$. This resulted in the removal of the offset in the acceleration signal due to the constant force of the gravitation. In 

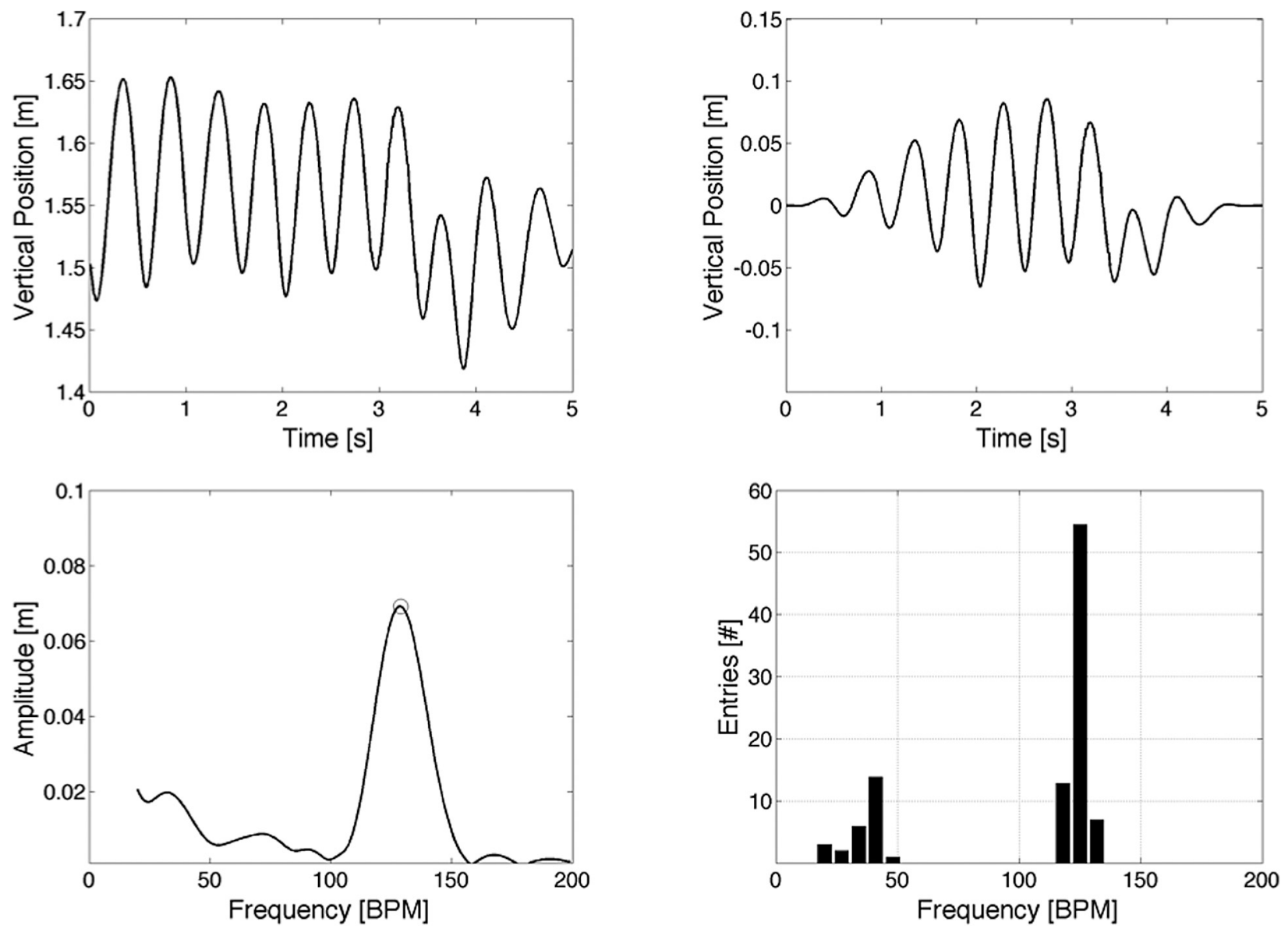

FIGURE 4. Example FFT graphs for the synchronization of one participant. The first graph represents the original input of movement data in a frame of five seconds. The second graph shows the same window after centering on zero and multiplying with a Hanning window. The third graph displays the frequency output containing the highest peak value in the range between 20 BPM and 200 BPM. The fourth graph shows the resulting histogram for a single piece of music of $30 \mathrm{~s}$.

addition, it reduced signals that were unrelated to the actual motion of the participants. The next step concerned the rectification of the signal and summation of the samples over the time period under study. Since a $3 \mathrm{D}$ sensor was used to measure acceleration, activity count consisted of the mean value of the RMS over the three directions:

$$
C=\frac{1}{N} \sum_{i=1}^{N} \sqrt{a_{x}\left(t_{i}\right)^{2}+a_{y}\left(t_{i}\right)^{2}+a_{z}\left(t_{i}\right)^{2}}
$$

where $N$ was the total number of samples in one BDL segment and $a_{\mathrm{x}, \mathrm{y}, \mathrm{z}}$ concerned the 3D acceleration measured at time $t_{\mathrm{i}}$. For each participant, activity count was calculated for each of the 21 segments in the music.

Tempo entrainment. In order to quantify entrainment with the tempo of the music, a frequency analysis of the positional data of each participant was performed. This analysis was carried out on the positional information in the vertical direction. The analysis was based on a fast Fourier transform (FFT). The input consisted of windows of data with a duration of $5 \mathrm{~s}$ (corresponding to 500 data points at $100 \mathrm{~Hz}$ sampling rate), zero padded to a total length of 6,000 samples in order to achieve a resolution of $1 \mathrm{BPM}$ in the frequency domain. Initially, each window of data was centered on zero to eliminate the frequency component at $0 \mathrm{~Hz}$, and multiplied with a Hanning window in order to minimize higher harmonics due to disruptive changes at the boundaries of the analyzed data set (see Figure 4). This analysis was repeated every $0.25 \mathrm{~s}$ to obtain a clear picture of the behavioral change of the participants. Movements from each musical fragment with different BDL were analyzed, and data obtained during 
transitions between these fragments were disregarded. The analysis resulted in $101 \mathrm{FFT}$ calculations for each musical fragment of $30 \mathrm{~s}$ (i.e., $(30$ " -5 ") $/ 0.25$ " +1$)$ and 41 FFT calculations for the solo fragments of 15 s (i.e., $\left.\left(15^{\prime \prime}-5 "\right) / 0.25 "+1\right)$. In each of the frequency spectra obtained, the highest peak was located in the range between 20 BPM and 200 BPM and its corresponding BPM value was used in the statistical analysis.

For each of the 21 segments in the music, the obtained BPM values found in the FFT analysis were added to a histogram with bins of 7 BPM-width, where either 128 BPM (one-beat periodicity) or 64 BPM (two-beat periodicity) was at the center of its corresponding bin. Both one-beat periodicity and two-beat periodicity were studied as adults are believed to be able to entrain to external rhythms over a great range of tempi, also at rates that are multiples or fractions of the same underlying pulse (e.g., Drake, Jones, \& Baruch, 2000; Large \& Palmer, 2002; Snyder \& Krumhansl, 2001). Double beat was not studied as $128 \mathrm{BPM}$ already proved to be quite fast. By combining the bins corresponding to 128 BPM and 64 BPM, it was possible to count the times the participants were entrained to the tempo of the music. Since there were either 101 or 41 frequency analyses performed for each musical segment of $30 \mathrm{~s}$ or $15 \mathrm{~s}$, respectively, these counts were added and scaled to a maximum of 100 , so the number represents the percentage of time during which the participants successfully entrained with the tempo of the music.

\section{Results}

Apart from the effect of the BDL on activity count and tempo entrainment, we also examined the effect of social interaction. Moreover, the effect of the participants' sex was studied.

\section{ACTIVITY COUNT}

We first examined whether there was any significant effect of the six songs on activity count. A Kolmogorov-Smirnov test (KS-test) showed that the assumption of normality could not be accepted. A Friedman's ANOVA with the songs as test variables showed a significant change in activity count over the songs, $\chi^{2}(5)=222.76, p<.05$.

Next, mean activity count over the six songs was calculated for each BDL. A Friedman's ANOVA with mean activity count as the test variable was used to check the effect of the different BDLs. This test showed a significant change in activity count over the BDLs, $\chi^{2}(2)=24.01, p<.05$. Wilcoxon tests were used to follow up this finding and a Bonferroni correction was

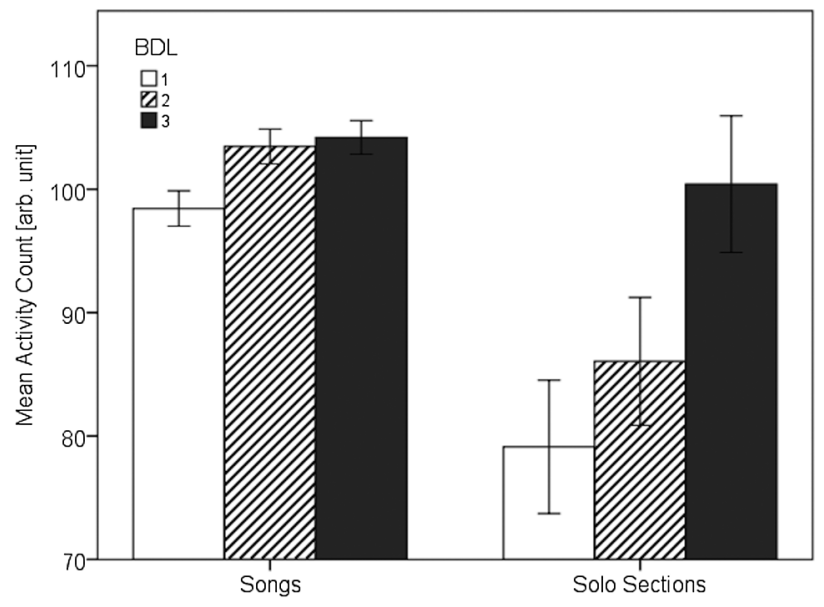

FIGURE 5. Mean activity count for the songs and solo sections as a function of BDL. Data presented are mean $\pm S E$.

applied. It appeared that activity count significantly increased from BDL 1 to BDL 2, $T=3597, p<.0167$, $r^{2}=.07$, and from BDL 1 to BDL $3, T=3773, p<.0167$, $r^{2}=.09$. No significant difference was found between BDL 2 and BDL 3 (see Figure 5).

When considering the solo bass drum sections, activity count changed also significantly over the BDLs, $\chi^{2}(2)=32.82, p<.05$. Activity count significantly increased from BDL 1 to BDL 2, $T=3409$, $p<.0167, r^{2}=.05$, from BDL 2 to BDL $3, T=3605$, $p<.0167, r^{2}=.07$, and from BDL 1 to BDL 3 , $T=4149, p<.0167, r^{2}=.15$ (see Figure 5).

\section{TEMPO ENTRAINMENT}

Only 14 of the 20 groups $(n=70)$ produced workable data sets from motion capture. The data of six groups were removed due to missing values caused either by occlusion of markers, or by participants dancing outside of the range of the camera system. Therefore, tempo entrainment data of only 70 participants is analyzed here.

Just as in the activity count analysis, we started by testing the effect of the songs on the participants' entrainment with the tempo of the music. A KS-test showed that the assumption of normality could not be accepted. A Friedman's ANOVA with the songs as test variables showed a significant change in tempo entrainment over the songs, $\chi^{2}(5)=59.97, p<.05$.

Subsequently, mean tempo entrainment over the songs was calculated and considered in the analysis. A Friedman's ANOVA with mean tempo entrainment as test variable revealed a significant change in tempo entrainment over the BDLs, $\chi^{2}(2)=55.80, p<.05$. It 


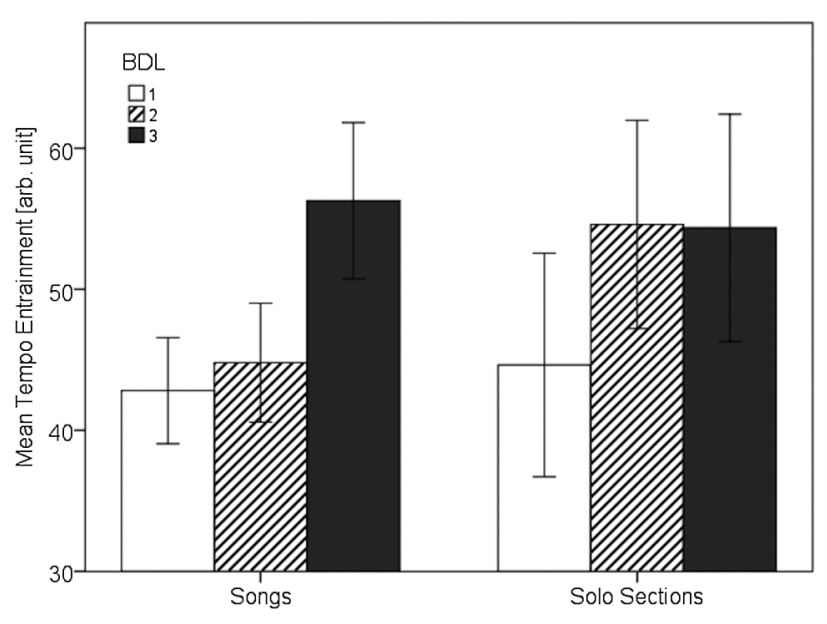

FIGURE 6. Mean tempo entrainment for the songs and solo sections as a function of BDL. Data presented are mean $\pm S E$.

appeared that tempo entrainment significantly increased from BDL 1 to BDL 2, $T=1642, p<.0167$, $r^{2}=.04$, from BDL 2 to BDL $3, T=2206, p<.0167$, $r^{2}=.23$, and from BDL 1 to BDL $3, T=2373, p<$ $.0167, r^{2}=.31$ (see Figure 6).

Also in the solo sections, a significant effect of the BDL on tempo entrainment was found, $\chi^{2}(2)=10.21$, $p<.05$. Tempo entrainment significantly increased from BDL 1 to BDL 2, $T=1678.50, p<.0167$, $r^{2}=.06$, and from BDL 1 to BDL $3, T=1548, p<$ $.0167, r^{2}=.06$. No significant effect was found between BDL 2 and BDL 3 (see Figure 6).

\section{JOINT ACTION}

Next, the effect of joint action was examined. Based on both activity count data and tempo entrainment data for all songs (including the solo sections) and BDLs, Pearson's correlation coefficients between all participants were calculated. Subsequently, mean Pearson's correlation coefficients between all groups were calculated for both activity count and tempo entrainment. Finally, mean coefficients of correlation within groups were compared with mean coefficients of correlation between different groups.

For both activity count and tempo entrainment, the assumptions of homogeneity of variances and normality could be accepted. Paired-samples $t$-tests with the mean coefficients of correlation within groups and the mean coefficients of correlation between different groups as test variables showed that, with regard to activity count, correlation coefficients were significantly higher within groups $(M=0.52, S E=0.04)$ than between different groups $(M=0.20, S E=0.02), t(19)=9.71, p<.05$, $r^{2}=.83$. With regard to tempo entrainment, correlation coefficients were again significantly higher within groups $(M=0.50, S E=0.05)$ than between different groups $(M=0.41, S E=0.02), t(13)=2.73, p<.05$, $r^{2}=.36$.

Sex. Finally, we examined whether there was any significant sex difference in average tempo entrainment, average activity count, or in response to the BDL. No significant difference was found concerning average tempo entrainment or concerning response to the different BDLs. Concerning activity count, a significant effect did appear. The average activity count over the songs and BDLs was calculated and used in the analysis. As the assumptions of homogeneity of variances and normality could be accepted, an independent $t$-test with the average activity count as test variable and sex as grouping variable showed that on average, female participants $(M=0.31, S E=0.01)$ displayed significantly more activity than male participants $(M=0.26$, $S E=0.01), t(98)=-2.24, p<.05, r^{2}=.05$.

\section{Discussion}

The present study investigated the effect of the sound pressure level of the bass drum on human dance movement. We presumed that an increase in the loudness of the bass drum could enhance tempo entrainment and activity count. In addition, a group effect and an effect of sex was expected to be uncovered. The kinematic analysis showed that participants did indeed embody the dynamic level of the bass drum. Analysis revealed that an intensification of the sound pressure level of the bass drum led to an increase in activity count. This finding is consistent with the idea that loudness generally results in more energetic movements of the listener (McNeill, 1995), a phenomenon often observed in dance clubs where DJs boost the volume of the bass drum in order to motivate the audience to move (McCown et al., 1997). It could also be linked with neuroscientific research, which emphasizes the extreme sensitivity of a particular element of the human vestibular system - the sacculus - to low-frequency and infrasound vibrations (Todd, Rosengren, \& Colebatch, 2008). According to this research, sensations of pleasure are believed to emerge when the sacculus is stimulated, and it would appear that triggering the sacculus using bass sounds also results in bodily responses as participants moved more actively to an increase in the bass drum loudness.

Alongside the influence of the bass drum on activity count, an effect was revealed with respect to tempo entrainment. Participants became more closely 
entrained with the tempo of the music subsequent to a rise in the loudness of the bass drum. Similar findings have been reported by Burger, Thompson, Saarikallio, Luck, and Toiviainen (2010), suggesting that music with a clear rhythmic structure in the low frequency range encourages participants to move on the spot, whereas structures in this frequency range which are not so clear tend to prompt locomotion, perhaps as if dancers were looking for the beat. Our finding is also in accordance with the idea that events with greater accent could cause greater period adjustments (Large \& Kolen, 1994). Additionally, an increase in the sound pressure level of the bass drum obviously facilitates beat perception, consequently, tempo perception; thus, it could facilitate tempo entrainment. It is worthwhile considering the overall level of audibility of the bass drum: it seems likely that, at particularly loud or soft overall levels, increases in bass drum volume might not lead to significant changes in bodily behavior, whereas at intermediate overall levels, the effects of variations in bass drum loudness on body movement might be more distinct. This is an issue worthy of further investigation.

Another interesting observation concerned joint action, as a group effect could be uncovered. Participants of the same group correlated stronger with each other than with participants of other groups. This finding could suggest that dancing in a group could have a positive influence on social bonding and behavioral coherency in groups of people, and therefore could facilitate group cooperation and mutual understanding (Freeman, 2000; Richman, 1987). However, this is a matter of some speculation and would benefit from further study.

With regard to sex, a general effect was uncovered as female participants moved more actively than their male counterparts. This observation could be explained by a study of Passmore and French (2001), which revealed that women are more likely to actively engage in dance activities than men. Moreover, Sanderson (2001) suggested that this difference in attitude to dance is already established during childhood. In her study, opinions were sought from a total of 1,668 girls and boys, aged between 11 and 16 years, using questionnaires that included dance attitude scales. Results showed that girls display more positive attitudes to dance than boys. Risner (2009) argued that the tendency of (particularly Western) men to display less positive attitudes to dance and to be less willing to dance than women, is due to the fact that the dominant Western paradigm positions dance as a predominantly female activity and art form. Therefore, males who dance (whether gay or straight) are always in danger of being stigmatized as effeminate.

An issue that was not considered in this study was that of personality, despite its being believed to play a role in the preference for loud bass sounds in music (McCown et al., 1997). Both psychoticism and extraversion are presumed to be positively related to the preference for enhanced bass. However, the data collected in this study did not allow any detailed investigation of the potential effects of personality.

This study aimed at creating an ecological setting through the employment of club-style lighting and contemporary dance music. The music was composed especially for this particular study, in order to ensure full control over every parameter in the music. Inevitably, it could be argued that the stimulus was in some way artificial. However, some ecological validity of the composition was ensured as it was created by both an experienced modern dance music composer and producer. Moreover, participants' assessments of the music proved to be particularly positive and besides, implementing existing music could have caused confounding effects due to familiarity.

A social condition was created, by studying the effect of the bass drum dynamics on groups of five participants, as motor entrainment generally occurs in social contexts (Kirschner \& Tomasello, 2010; Repp \& Keller, 2008). Future work might investigate the effect of the sound pressure level of the bass drum both on larger groups of participants (for example, in an actual dance venue) and on participants dancing alone (for instance, in front of a mirror or without any means of monitoring their movements). In such conditions, the level of the bass drum might still be expected to affect participants' movements. However, whether the sound pressure level of the bass drum could affect movements of a single participant and of large groups of participants should be investigated in further studies.

To our knowledge, this study is pioneering in examining the excessive bass drum sound, which is so essential for popular dance music. As the sound pressure level of the bass drum increased, activity count and tempo entrainment increased as well. This suggests a strong causal effect of bass drum loudness on movement. These findings demonstrate that, in addition to its function as a stylistic element, the bass drum has a strong impact on dancing itself.

\section{Author Note}

Edith Van Dyck acknowledges the Ghent University EmcoMetecca project for a doctoral grant. This long- 
term project aims at closing the gap between musical experience and the digital/electronic environments that provide this experience. The authors also wish to thank Luiz Naveda for photography, Annelies Bockstael for assisting with the sound pressure level measurements,
Ivan Schepers for technical support, and Jonathan Hargreaves for proofreading the article.

Correspondence concerning this article should be addressed to Edith Van Dyck, Blandijnberg 2, 9000 Ghent, Belgium. E-mail: edith.vandyck@ugent.be

\section{References}

Appenzeller, T. (1998). Evolution or revolution. Science, 282, 1451-1454.

Bengtsson, I. (1973). Understanding: Prolegomena of a semiotic-hermeneutic approach. In P. Faltin \& H.-P. Reinecke (Eds.), Music and understanding: Approaches to the semiotic theory, aesthetics and sociology of musical perception (pp. 11-36). Köln: Arno Volk Verlag.

Bramble, D. M., \& Lieberman, D. E. (2004). Endurance running and the evolution of Homo. Nature, 432, 345-352.

Brown, W., Cronk, L., Grochow, K., Jacobson, A., Liu, C. K., Popvic, Z., \& Trivers, R. (2005). Dance reveals symmetry especially in young men. Nature, 438, 1148-1150.

Brown, S., Martinez, M. J., \& Parsons, L. M. (2006). The neural basis of human dance. Cerebral Cortex, 16, 1157-1167.

Burger, B., Thompson, M. R., Saarikallio, S., Luck, G., \& Toiviainen P. (2010, August). Influence of musical features on characteristics of music-induced movements. Paper presented at the $11^{\text {th }}$ International Conference on Music Perception and Cognition, Seattle, WA.

Chen, J. L., Penhune, V. B., \& Zatorre, R. J. (2008). Listening to musical rhythms recruits motor regions of the brain. Cerebral Cortex, 18, 2844-2854.

DARWIN, C. (1871). The descent of man, and selection in relation to sex. London, UK: John Murray.

De Bruyn, L., Leman, M., Moelants, D., \& Demey, M. (2009). Does social interaction activate music listeners. In S. Ystad \& R. Kronland-Marinet (Eds.), Computer Music Modeling and Retrieval (pp. 93-106). Heidelberg: Springer Verlag.

Dibble, K. (1995). Hearing loss and music. Journal of the Audio Engineering Society, 43, 251-266.

Drake, C., Jones, M. R., \& Baruch, C. (2000). The development of rhythmic attending in auditory sequences: Attunement, referent period, focal attending. Cognition, 77, 251-288.

Drake, C., Penel, A., \& Bigand, E. (2000). Tapping in time with mechanically and expressively performed music. Music Perception, 18, 1-24.

Edworthy, J., \& Waring, H. (2006). The effects of music tempo and loudness level on treadmill exercise. Ergonomics, 49, 1597-1610.

Freeman, W. (2000). A neurobiological role of music in social bonding. In N. L. Wallin, B. Merker, \& S. Brown (Eds.), The origins of music (pp. 411-424). Cambridge, MA: MIT Press.
Gill, S. P. (2007). Entrainment and musicality in the human system interface. AI and Society, 21, 567-605.

Grahn, J. A., \& Brett, M. (2007). Rhythm and beat perception in motor areas of the brain. Journal of Cognitive Neuroscience, 19, 893-906.

Janata, P., \& Grafton, S. T. (2003). Swinging in the brain: Shared neural substrates for behaviors related to sequencing and music. Nature Neuroscience, 6, 682-687.

Kirschner, S., \& Tomasello, M. (2010). Joint music making promotes prosocial behavior in 4-year-old children. Evolution and Human Behavior, 31, 354-364.

Large, E. W., \& Jones, M. R. (1999). The dynamics of attending: How people track time-varying events. Psychological Review, 106, 119-159.

Large, E. W., \& Kolen, J. F. (1994). Resonance and the perception of musical meter. Connection Science, 6, 177-208.

Large, E. W., \& Palmer, C. (2002). Perceiving temporal regularity in music. Cognitive Science, 26, 1-37.

Leman, M. (2007). Embodied music cognition and mediation technology. Cambridge, MA: MIT Press.

Madison G., Gouyon F., Ullén F., \& Hörnström, K. (2011). Modeling the tendency for music to induce movement in humans: First correlations with low-level audio descriptors across music genres. Journal of Experimental Psychology: Human Perception and Performance, 37, 1578-1594.

McCown, W., Keiser, R., Mulhearn, S., \& Williamson, D. (1997). The role of personality and gender in preference for exaggerated bass in music. Personality and Individual Differences, 23, 543-547.

McKeOn, R. P. (Ed.). (2001). The basic works of Aristotle. New York: Modern Library.

McNeill, W. H. (1995). Keeping together in time: Dance and drill in human history. Cambridge, MA: Harvard University Press.

Merker, B. H., Madison, G. S., \& Eckerdal, P. (2009). On the role and origin of isochrony in human rhythmic entrainment. Cortex, 45, 4-17.

Moelants, D. (2008, August). Hype vs. natural tempo: A long-term study of dance music tempi. Paper presented at the $10^{\text {th }}$ International Conference on Music Perception and Cognition, Sapporo, Japan.

Passmore, A. E., \& French, D. (2001). The development and administration of a measure to assess adolescents' leisure participation. Adolescence, 36, 67-75. 
Phillips-Silver, J., \& Trainor, L. J. (2007). Hearing what the body feels: Auditory encoding of rhythmic movement. Cognition, 105, 533-546.

Phillips-Silver, J., \& Trainor, L. J. (2008). Vestibular influence on auditory metrical interpretation. Brain and Cognition, 67, 94-102.

Phillips-Silver, J., Aktipis, C. A., \& Bryant, G. A. (2010). The ecology of entrainment: Foundations of coordinated rhythmic movement. Music Perception, 28, 3-14.

Phillips-Silver, J., Toiviainen, P., Gosselin, N., Piché, O., Nozaradan, S., Palmer, C., \& Peretz, I. (2011). Born to dance but beat deaf: A new form of congenital amusia. Neuropsychologia, 49, 961-969.

Repp, B. H. (2005). Sensorimotor synchronization: A review of the tapping literature. Psychonomic Bulletin and Review, 12, 969-992.

Repp, B. H., \& Keller, P. E. (2008). Sensorimotor synchronization with adaptively timed sequences. Human Movement Science, 27, 423-456.

Richman, B. (1987). Rhythm and melody in gelada vocal exchanges. Primates, 28, 199-223.

Risner, D. (2009). What we know about boys who dance: The limitations of contemporary masculinity and dance education. In A. Shay \& J. Fisher (Eds.), When men dance: Choreographing masculinities across borders. New York: Oxford University Press.

Sanderson, P. (2001). Age and gender issues in adolescent attitudes to dance. European Physical Education Review, 7, 117-136.

Snyder, J., \& Krumhansl, C. L. (2001). Tapping to ragtime: Cues to pulse finding. Music Perception, 18, 455-489.
Todd, N. P. M., Cody, F. W., \& Banks, J. R. (2000). Saccular origin of frequency tuning in myogenic vestibular evoked potentials? Implications for human responses to loud sounds. Hearing Research, 141, 180-188.

Todd, N. P. M., Rosengren, S. M., \& Colebatch, J. G. (2008). Tuning and sensitivity of the human vestibular system to low-frequency vibration. Neuroscience Letters, 444, 36-41.

Toiviainen, P., Luck, G., \& Thompson, M. (2010). Embodied meter: Hierarchical eigenmodes in music-induced movement. Music Perception, 28, 59-70.

Trainor, L. J., Gao, X., Lei, J., Lehtovaara, K., \& Harris, L. R. (2009). The primal role of the vestibular system in determining musical rhythm. Cortex, 45, 35-43.

Ulyate, R., \& Bianciardi, D. (2002). The interactive dance club: Avoiding chaos in a multi-participant environment. Computer Music Journal, 26, 40-49.

WARD, C. V. (2002). Interpreting the posture and locomotion of Australopithecus afarensis: Where do we stand? Yearbook of Physical Anthropology, 35, 195-215.

Williams, W., Beach, E. F., \& Gilliver, M. (2010). Clubbing: The cumulative effect of noise exposure from attendance at dance clubs and night clubs on whole-of-life noise exposure. Noise and Health, 12, 155-158.

Wiltermuth, S. S., \& Heath, C. (2009). Synchrony and cooperation. Psychological Science, 20, 1-5.

Zatorre, R. J., Chen, J. L., \& Penhune, V. B. (2007). When the brain plays music: Auditory-motor interactions in music perception and production. Nature Reviews Neuroscience, 8, 547-558. 
